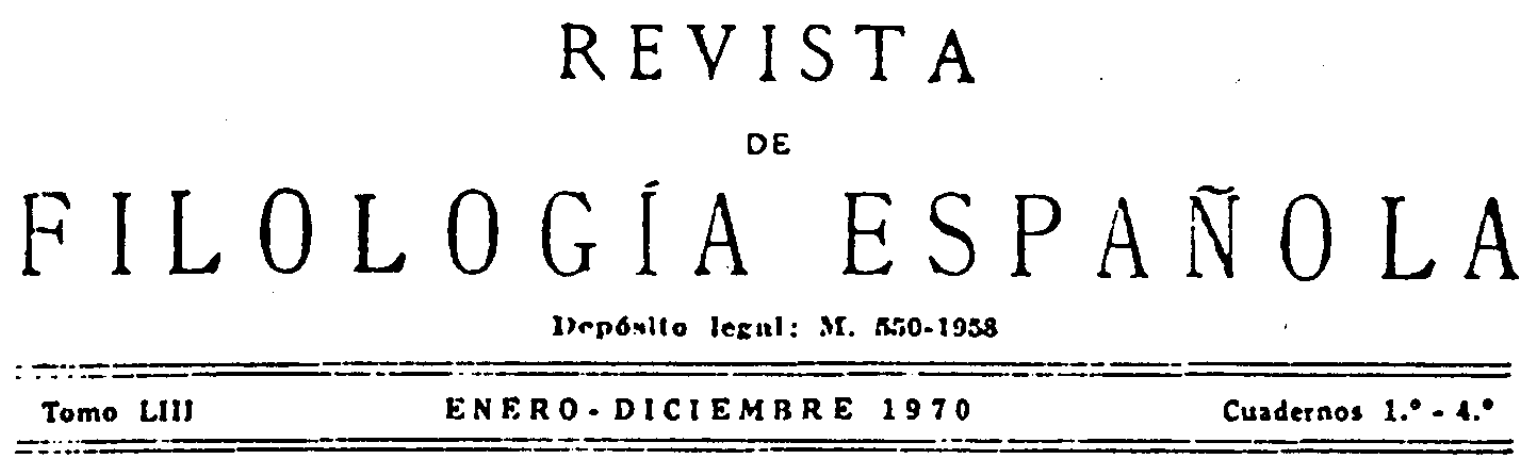

\title{
LA LENGUA DEL «PERSILES»
}

La lengua de Cervantes

En razón directa a la magnitud de su obra, y a lo que Cervantes significa en las letras españolas y universales, sorprende la escasez de buenos estudios sobre la lengua de Cervantes.

Naturalmente, estudios no faltan (y aun extensos libros). I,o que ocurre es que el resultado está casi siempre lejos de corresponder a la capacidad que requiere una labor de este calibre. Por eso, dentro de un nutrido material, son realmente pocos los aportes que nos aclaran tema tan enorme y delicado; aparentemente fácil y, sin embargo, de extraordinaria complejidad.

De manera especial, recuerdo ahondamientos parciales de Rodríguez Marín, Menéndez Pidal, Rafael Lapesa, María Rosa Lida de Malkiel, Helmut Hatzfeld, y, sobre todo, como estudio general, el buen tributo de Angel Rosenblat titulado La lengua de Cervantes ${ }^{1}$.

Rosenblat, apoyándose en ejemplos del Quijote, enfoca su estudio dentro de una ya aceptada y útil disposición. Primero, la actitud de Cervantes ante la lengua; y, posteriormente, la realidad de la lengua cervantina.

En el primer caso, la actitud de Cervantes ante la lengua se muestra tanto en lo que defiende como en lo que ataca. Defiende el romance castellano y la dignificación del habla popular. Combate la afectación, los arcaísmos y la vulgaridad. De todo esto deduce el crítico que el ideal lingüistico de Cervantes puede sintetizarse en un nombre: la discreción.

En la parte que centra su estudio, Rosenblat distingue en la lengua literaria de Cervantes los siguientes rasgos: a) la antitesis; b) el juego

1 Angrit, Rosinblat, La lengua de Cervantes. (Cervanles, Facultad de Filosofia y I,ctras de Caracas, Caracas, I949.) 
con el tópico o el lugar común; c) los juegos de palabras; d) el juego con la forma gramatical; e) el juego con planos distintos del lenguaje; f) la repetición deliberada; $g$ ) el juego con la elipsis, y $h$ ) los sinónimos voluntarios.

Se ocupa después (para defender a Cervantes) de las llamadas uincorrecciones del Quijole». Vale decir, de ese capitulo, que solfa aparecer aún entre los cervantistas, en el afán de pesar, con discutibles "gramáticas", méritos y defectos de la obra inmortal ${ }^{1}$. Concluye, finalmente, nuestro crítico con una síntesis valorativa de la lengua cervantina.

El estudio de Rosenblat, que - repito- es, en realidad, un estudio sobre la lengua del Quijote, revela (como era de esperar de él) un trabajo bien construido y con los ejemplos adecuados.

Por su parte, en meditada síntesis (explicable, por otro lado, dentro de la obra general ell que aparecen los párrafos), Rafael Lapesa sintetiza el ideal cervantino de la lengua con la misma idea de Juan de Valdés: "habla llana regida por el juicio prudente». Y señala que el estilo típico de Cervantes es el de "la narración realista y el diálogo familiar. I a frase corre suelta, holgada en su sintaxis, con la fluidez que conviene a la pintura cálida de la vida... Esa facilidad inimitable, compañera de un humorismo optimista y sano, superior a todas las amarguras es la eterna lección del lenguaje cervantino...." 2 .

I apesa considera, además, que, si bien se encuentran igualmente en Cervantes los juegos con los conceptos o con el cuerpo fónico de los vocablos, la abundancia de epítetos y simetrías, diversas formas retóricas ampulosas, y las imitaciones - conscientes e inconscientes- de los libros de caballerías, tales particularidades no alteran el predominio que destacó en un principio. De nuevo, toma como ejemplo por excelencia al.Quijote (aunque habría que distinguir, a veces, entre el Quijote de I605 y el de I6I5).

1 Ya Mrenisdiz Pidar, en la breve introducción a Cervantes que ilustra su Antología de prosistas castellanos (ver ed. de Madrid, 1920, pp. 219-220) habia defendido a Cervantes del rigor de Clemencín, Fartzenbusch y otros...

2 Cf. RAFAEL LAPESA, Historia de la lengua española, Madrid, 1959, pp. 22022I. Ver, también, MIriḱndez PIDAL: "La sintaxis de Cervantes es, en general, como la del Lazarillo de Tormes. La de la lengua familiar que sigue con ligereza el pensamiento, sin preocuparse de aquella trabazón inflexible que obliga al pensamiento a seguir los lentos pasos de la lógica gramatical... (Cf., Antologia de prosistas castellanos, ed. citada, p. 2rg.) Menéndez Pidal distingue tres uestilos* en Cervantes. Iste (aqui sintetizado) como el más típico; el más trabajado y artificioso de La Galatea y El Persiles; y el pasajero y contrahecho que remeda el de los libros de caballerías. (Id., pp. 219-220.) 
Una especie de lugar común en los estudios dedicados al Persiles consiste en subrayar en él el sello de la heterogeneidad. Heterogeneidad de los distintos materiales y partes, $y$, naturalmente, de la lengua que se le atribuye. Hasta sorprende ver cómo coinciden aquí criticos de muy diversa formación y tendencias.

De más está decir que la estimación valorativa del Persiles suele hacerse a la luz de lo que el Quijote, en globo, significa. Es muy diff́cil - casi imposible- encontrar un lector (no midamos calibres) que haya leido el Persiles antes que el Quijote. La comparación, pues, aparece ampliamente justificada.

De la misma manera, no podríamos oponer a la caracterización de "heterogeneidad" un juicio que, con afán de defensa, pretendiera cambiarlo radicalmente. Sin embargo, creo que podemos aspirar a ver mejor o, por lo menos, a pretender captar los altibajos del Persiles.

Citemos algunas opiniones. Para Menéndez y Pelayo, el Persiles "contiene en su segunda mitad alguna de las mejores páginas que escribió su autor. Pero hasta que pone el pie en terreno conocido y recobra todas sus ventajas, los personajes desfilan ante nosotros como legión de sombras..." 1. Dijo Menéndez Pidal: "Aparte de tal estilo [es decir, el más personal y valioso]... empleó Cervantes otro... más trabajado y artificioso, a la manera que usaban generalnente los que estudiaban los autores latinos e italianos. Este se ve en su primera obra, La Galatea, en la última que escribió, el Persiles y Sigismunda, y en los episodios de tono sentimental e idealista que se intercalan en el Quijote» ${ }^{2}$. Esto escribió María Rosa Lida de Malkiel: "En cuanto al estilo, ¿qué lector no perdonará el amaneramiento anticuado de muchas páginas del $P e r-$ siles en gracia a lo castizo y jugoso de las restantes?..." ${ }^{3}$.

Juicios que, por cierto, podemos aceptar, en general, con mucho más fundamento que el malhumorado y poco justo comentario que estampó

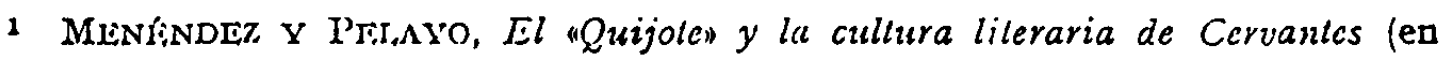
Estudios de critica histórica y literaria, I. Bucnos Aires, 1944, p. 336). Antes, babia cscrito Ticknor: "Tanıién es preciso confesar que el estilo del Persiles y Sigismunnda es más acabado y esmerado que el de ningín otro de sus escritos; lo cual no quita que el trabajo sea muy inferior a lo que el autor $y$ sus amigos creían cuando le calificaban de modelo en su género, y del mejor libro que escribió Cervantess (J. TICkNoR, Historia de la literatura española, trad. de P. DE GAYANGos y E.ni: VEDIA, II, Madrid, I851, p. 238.)

2 Minéndiz Pidar, Anlología de prosistas castellanos, ed. citada, p. 220.

3 MLRí Rosa Lida DE MALrris, Argenis o de la caducidad del arte, en Es. tudios de literatura española y comparada, Buenos Aires, 1960, p. 237. 
Benedeto Croce: «Stupisce che si lodi la bellezza dello stile che é invece tutto pieno di scialbe formula generiche che non parlano alla fantasia onde, per esempio, sempre che accade di presentare una bella persona, vi si dirá che é "hermosa", anzi "hermosísima», anzi di "una maravillosa hermosura" o la si paragona a una "dea", e cosí via per tutte le descrizioni, fisiche o morali, che sono nel libron ${ }^{1}$.

Un análisis detallado de la lengua del Persiles (procuraré mostrarlo) prueba sin lugar a dudas que ella no puede reducirse al único ejemplo encadenado que cita Croce, ni que tal perfil corresponde -como el crítico italiano afirma - a todas las descripciones físicas o morales que. están en el libro...

Sin afán de ver en el Persiles una obra de extremada maestría ${ }^{2}$, la verdad es que contiene más aciertos de los que comúnmente se le atribuyen. Junto a ellos, elementos neutros, y, en el lugar más bajo, la retórica menos defendible.

Es evidente la preocupación por la lengua que tuvo Cervantes al elaborar el Persiles. Preocupación y cuidado que se corresponde (por lo que sabemos) con el anticipo que va haciendo, en distintos prólogos y obras, del libro anunciado. Cuidado, en cuanto se nota a menudo el trabajo lento del escritor, su deseo de lograr claros efectos «literarios», y hasta alardes efectistas que, ciertamente, no se le conocian.

Es verdad que el ámbito de la acción (salvo una parte de la obra) difiere del que conocemos a través del Quijote. De todos modos, y sin dejar de distinguir entre el Quijote de I605 y el de I6I5, el Persiles pocas veces

1 Cf. B. CROCE, Cervantes, Persiles y Sigismunda, en Quaderni della critica, Bari, 1948, núm. 12, p. 75.

2 Como vemos, por ejemplo, en algunos juicios (a veces, quizás, con el exceso de la defensa): "Ante todo, reparad en el estilo. Comparad esta prosa -la mejor que ha escrito Cervantes- con la prosa de los Cigarrales, de Tirso, o de El Peregrino en su Patria, de Lope. En Cervantes todo es sencillez, limpieza, diafanidad; en Tirso y Lope, todo enmarañamiento, profusión, palabrerda vacua y bambolla. No se puede parangonar esta prosa postrera de Cervantes sino a los últimos e insuperables cuadros de Velázquez... Q Qué prosa más fina y más claral... 1Qué prosa mús fina y más claral.... (AzORín, Al margen del "Persiles", en $A l$ margen de los cld́sicos (I915), ver Obras completas, III, Madrid, 1947, pp. 219-220.) Indudablemente, Azorín se deja llevar demasiado de su entusiasmo reivindicador... - Los trabajos de Persiles y Sigismunda, aún sin estudiar con detenimiento, de los que Cervantes se mostraba tan orgulloso, encierra bellezas perfectas. El Persiles, rel último sueño romántico de Cervantes», según frase de Farinelli, es un libro asaetado por la mejor poesía en prosa de todo el siglo XVIr. Su estilo, tan trabajado y plido, se nota lo mismo en la prosa que en los escasos poemas que se intercalaw... (Joseph M. CraUBE, La poesia lírica de Cervantes, en Insula, Homenaje a Cervantes, Madrid, 1947, p. 185.) 
muestra la lengua familiar y las caracterfsticas inconfundibles que particularizan a su obra más famosa. Conviene agregar también, para que no se interpreten mal mis palabras, que cuidado no supone indefectiblemente acierto o rasgo feliz. A veces, sí, la labor extremada, de pulidez, repercute eu el logro; otras veces, sólo en la frase fría o en la gala aparatosa, recargada.

Es curioso observar cómo, en distintos enfoques críticos, el Persiles es colocado junto a La Galatea. Y las dos obras, como paradigma de la lengua "retocada" o "artificiosa" (son palabras de los críticos) de Cervantes. Por este camino no puede extrañarnos (ya lo he indicado) que algunos eruditos hayan visto en La Galatea y el Persiles el punto de origen del "culteranismo" '. Creo, sill embargo, que tal sospecha no tiene mayor fundamento.

Después de lo dicho, y como anuncio de un análisis más detallado, considero que los rasgos salientes de la lengua literaria de Cervantes en el Persiles son los que se marcan con la preseucia y reiteración de los siguientes elementos: a) la construcción trimembre (tres sujetos, tres complementos, tres adjetivos, etc.); b) el adjetivo (abundancia y persoualización); c) la abundancia de superlativos (e bipérboles); d) la antítesis; e) los juegos de palabras (por repetición, derivación, paronomasia, etc.); f) las repeticiones intencionadas (paralelismos y encadenamientos); $g$ ) las frases hechas, y h) otros rasgos (hipérbaton, polisindeton, metáforas novedosas).

\section{a) La construcción trimembre}

Me ha llamado la atención la forma en que Cervantes construye frases trimembres, o dispone tres adjetivos en serie, o tres sujetos, o tres complementos.

No pretendo deducir de esta forma particular la imagen de la Trinidad, que tanto reflejo literario tuvo en obras medievales. Claro está. Pcro no deja de ser llamativa la reiteración, sobre todo si atendemos al peso que lo religioso tiene en el Persiles. Quizás un pasaje del libro que se refiere a las tres imágenes tenga algún sentido simbólico. Puede ser, si bien no es muy claro. Sólo cabe, en fin, destacar este procedimiento literario, si no de los más felices de Cervantes, por lo menos como elemento caracterizador:

1 Ver Martinez Mariula (según ADOLFO DE CASTRo, prólogo a su edición de los Poelas líricos de los siglos XVI y XVII, II, Madrid, 1857, p. V) y CESARE DE LOLLIS, Cervantes reazionario, Florencia, I947, p. 207. 
.... con que dejo admirados, atónitos y suspensos a cuantos alli estaban..." (Libro I, cap. IV.)

"Quedóse Candia lejos, y sirvió en su lugar agua pura, liınpia y frigidisima... (Libro $I$, cap. V.)

... porque me habla granjeado muchos, fuertes y poderosos enemigos...v (Libro I, cap. V.)

"Vieron mis diferentes géneros de muertes de quien la cólera, sinrazón y cuojo suelen ser inventores...* (Libro I, cap. VI.)

El capítulo $\mathrm{X}$ del Libro I, quizás identificado con el relato del uenamorado portugués», ofrece acumulados, llamativos ejemplos:

'Yo, señores, soy portugués de nación; noble de sangre, rico en los bienes de fortuna $y$ no pobre ell los de naturaleza..."

4...salió a verne a una sala, y salieron con ella la lonestidad, la gallorilia $y$ el silencion.

"Leonora, mi hija, es obediente, y mi mujer desea darme gusto, y yo tengo el deseo que he dicho: que con estas tres cosas, me parece que puede esperar vuesa merced buen suceso en lo que deseo."

"Ni la hermosa Leonora ni su madre me dijerou palabra, ui yo pude, como he dicho, decir algma.»

Sigamos con otros capitulos:

-De tal manera causó admiración, espanto y asombro la bellísima cscuadra en los de la mar y la tierra... (Libro I, cap. XI.)

-... Transila, hermasa como el sol, brava como una leoua y airada como una tigrew. (Libro I, cap. XII.)

-.. por excusar el ruido espantoso de los truenos, y la interpolada luz de los relámpagos, y el confuso estruendo de los marineros». (Libro II, cap. I.) 4... sin que por esto sea soberbia, desabrida y descuidada...) (Libro II, cap. VII, primera parte.)

"Todo se lo halla hecho, todo fácil, todo llano..." (Libro III, cap. II.)

*.. por venirle a la imaginación un grandísimo deseo de componer de todos ellos una comedia; pero no acertaba en qué nombre le pondria: si le llamaria comedia, o tragedia, o tragicomedia; porque, si sabia el principio, ignoraba el medio y el fin..." (Libro III, cap. II.)

-Dábales asiento la verde hierba de un deleitoso pradecillo: refrescábales los rostros el agua clara y dulce de un pequeño arroyuelo que por entre las hierbas corria; servianles de nuralla y de reparo muchas zarzas Y cambroneras que casi por todas partes los rodeaban...* (Libro III, cap. IV.) (III.)

"... un plato de una fresca, verde y sabrosa ensalada." (Libro III, cap.

C... vicron la junta, los besos y los abrazos que se daban los dos fanosos rios Ifcnares y Tajo." (Libro III, cap. VIII.)

"Las alquerias, caserios y lugares que hay por estos contormos..." (Libro III, cap. XVIII.)

"Confuso, atónito y espantado, estuvo por irse, sin hablar palabra a Persiles y Sigismunda... (Libro IV, cap. XIV.) 


\section{b) El adjelivo}

Si bien Cervantes mostró siempre especial afición por el adjetivo, no deja de sorprender la abundancia que encontramos en el Persiles. Naturalmente, no se trata de un rasgo extremadamente inusitado. l'cro, al repetir el esquema en forma llamativa, termina por conceder curacteristicas personalizadoras a la prosa del Persiles.

Lo dicho no equivale a afirmar que cada sustantivo lleve en la obra su corrcspondiente pareja adjetiva. Claro que si por un lado, y como norna, no llega a tanto, por otro lado vemos que, con frecuencia, un adjetivo solo no le basta, y necesita dos o más. Concretamente, Cervantes necesita a menudo calificar, determinar, como si lo empujaran ansias de precisiones. Fiebre, casi, que poco o nada quiere dejar, dentro de este sector, a la imaginación del lector.

Fácil es comprender que tales urgencias aparecen, sobre todo, cuando Cervantes se refiere a los dos personajes principales: Persiles y Sigismunda, o, si se quiere, Periandro y Auristela. Personajes a través de los cuales se ve, especialmente, el mundo novelesco que da perfil a la obra. Pues bien, de ellos se extiende también a los otros personajes esta particularidad. Descripciones y retratos son marcos apropiados, aunque no ínicos, para su disparar de adjetivos:

*Scutóse el fatigado joven, y tendiendo la vista a todas partes, casi junto a él, descubrió un navio que en aquel reposo del alterado mar, como en seguro puerto, se reparaba..." (Libro I, cap. I.)

4... pero cono le acosaban varios y tristes pensamientos, no podia el sucño tomar posesión de sus sentidos, ni menos lo consintierou unos congojosos suspiros y unas angustiadas lamentaciones que a sus oidos llegaron..." (Libro I, cap. II.)

"... vi que era simpleza oponer mi débil barca a su furia, $y$, con mis flacas y desmayadas fuerzas, a su rigor..." (Libro I, cap. II.)

"IFue obedecido al punto, $y$, al misno instante, tendieron por el suelo pieles curtidas, olorosas, limpias y lisas, de animales, para que de inantcles sirviesen..." (Libro I, cap. IV.)

a... y cul esto salió por la puerta del claustro la sin par Leunora, acompañada de la priora $y$ cle otras muchas monjas, vestida de raso blanco acuchillado, con saya entera a lo castellano, tomarlas las cuchilladas con ricas y gruesas perlas. Venia forrada la saya en tela de oro verde; traia los cabcllos sucltos por las espaldas, tan rubios, que deslumbraban los del sol, y tan luengos, que casi besaban la tierra; la cintura, collar y anillos que trafa, opiniones lubbo que valia un reino; torno a decir que saljó tan bclla, tau costosa, tan gallarda y tan ricameute compuesta y adoruada, que causb envidia en las mujeres y admiración en los hombres..." (Libro I, (ap. X.) 
- Amanecio en esto; volvieron las barcas al agua, pareciéndoles que el mar les esperaba sosegado y blando; $y$, entre tristes y alegres, entre temor y esperanza, siguieron su camino..." (Libro I, cap. XI.)

"Quién trac a vucstras vencrables canas y a vuestros causados aũos por ticrras tan apartadas de la viestra? (Libro I, cap. XI.)

4... levantó cádios viciosos y derribó levantados virtuosos; cumplio sus gustos, tan torpe como públicanente, en menoscabo de la autoridad del rey, y en muestra de sus torpes apetitos..." (Libro I, cap. XIV.)

... aqui debajo destos polres techos, o en los dorados de la famosa Roma; y asimismo te ofrezco de contenerme en los limites de la honestidad y buen decoro, si bicn vicse consumirne en los ahincos y deseos que trae consigo la concupiscencia desenfrenada y la esperanza propicia, que suele fatigar más que la apartada.s (Libro I, cap. XVI.)

* Al zarpar los hicrros y tirar las áucoras, disparó asi la gruesa como la menuda artilleria; rompieron los aires los sones de las chirimias y los de otros instrumentos músicos y alegres... (Libro I, cap. XVIII.)

"La nieve de la desierta playa les pareció blanda arena, y la soledad compañia... (Libro I, cap. XIX.)

"Con los años verdes, y con la hermosura mucha, con la libertad demasiada y con la rigueza abundante, se fucron apoderando de mi los vicios.... (Libro I, cap. XX.)

-... pues por sus cuartos la hacian a las mansas y hermosas ovejuelas que debajo de su solicitud y vigilancia se amparaban. (Libro I, cap. XXI).

-... descubrió sus dilatadas espaldas, sus auchos y fortísimos pechos, y los nervios y músculos de sus fucrtes brazos, con los cuales, y con destreza y maña incrcible, hizo que las cspaldas de los seis lucliadores, a despecho y pesar suyo, quedasen impresas en la ticrra*. (Libro I, cap. XXII).

-... se dejaron calar casi hasta la postrera parte del navio, por excusar el ruido espantoso de los truenos, y la interpolada luz de los relámpagos y el confuso estruendo de los marineros.... (Libro II, cap. I.)

a... y no lejos cstaba un puerto capacisimo de muchos bajeles en cuyas aguas, como en espejos claros, se estaba mirando una ciudad populosa, que, por una alta loma, sus vistosos edificios levantaba.» (Libro II, cap. II.)

4... como hacen los que, libres de la esclavitud turquesca, con las cadenas al hombro, habiéndolas quitado de los pies, cuentan sus desventuras con las primeras voces y liumildes plegarias en ticrra de cristianos." (Libro II, cap. V.)

a... gran cantidad de verdes y hojosos árboles, a quien servian de cristalinos espejos sus transparentes aguas... "(Libro II, cap. $\mathrm{X}$ )

"Dcjaron sus licrbosos lechos las clamas y los varones sus duras piedras, y salicron a ver descle aquella cumbre la amenidad de la pequeña isla...* (Libro II, cap. XVIII.)

.... en estos árboles, en estas hierbas y plantas, en estas claras fuentes, en estos bulliciosos y frescos arroyuelos... (Libro II, cap. XIX.)

"OOh, vida solitaria - dijo- santa, libre y segura, que infunde el cielo en las regaladas imaginaciones/ (Libro II, cap. XIX.) 
YYa salía de Belén en nuevo escuadrón de la nueva hermosura: Ricla, mediauamente hermosa, pero extremadamente a lo bárbaro vestida; Constanza, hermosisima y rodeada de pieles...* (Libro III, cap. I.)

-Dábales asiento la verde hierba de un deleitoso pradecillo; refrescábales los rostros el agua clara y dulce de un pequeño arroyuclo que por entre las hicrbas corria..." (Libro III, cap. IV.)

¿Va el primer alcalde, manso y piadoso, blando y conpasivo, dijo...* (Libro III, cap. X.)

"La bella matadora, dulce enojada, verdugo agradable... (Libro III, cap. XVII.)

-Sollozando estaba Periandro, en compañia del manso arroyuelo y de la clara luz de la noche; hacianle los árboles compañia, y un aire blando y fresco le enjugaba las lágrimas... (Libro IV, cap. XII.)

Ein fin, aunque entre en características generales de la lengua de su tiempo, podemos considerar de manera especial un particular uso de los cpitetos en Cervantes, epítetos fáciles de notar en muchas de las citas precedentes 1.

\section{c) El superlativo (y la hipérbole)}

I,as ausias del adjetivo toman aún dirección particular en la nutrida seric de superlativos que encontramos en la prosa cervantina. Mejor dicho: los superlativos y las hipérboles aparecen en el Persiles como la consecuencia directa de un mundo de idealización y perfecciones hacia las cuales el autor tiende.

De nuevo, en buena medida tal rasgo es el reflejo que despiden los dos personajes principales de la obra. Para referirse a ellos (retratos, acciones, reacciones) Cervantes recurre a menudo a superlativos e hipérboles. La peregrinación, la meta perseguida (Roma) y el peso que lo religioso tiene en el desarrollo de la novela, todo contribuye a extender, si cabc, tales particularidades expresivas. Le ahí, también, que superlativos c hipérboles se extiendan - como digo- a otros personajes, y fucra ya de lugares o episodios en que el autor coloca a Persiles y Sigismunda. Veamos ejeniplos.

1 O como puntualizaba Rafael Lapesa: "La visión platónica de una naturaleza perfecta invitaba a destacar por medio de epitetos aquellas cualidades con las que scres y cosas respondian inejor a sus arquetipos: "agua corriente y clara", "robusla y verde encina", "el blanco lirio y colorada rosa... (R. LAPESA, Historia de la lengua española, ed. citada, p. 206.) 
t... o ya del demonio, o ya de un antiguo hechicero a quien ellos tienen por sapientisimo varón... Estas doncellas compradas o robadas son bien tratadas de ellos, que sólo en esto muestran no ser bárbaros, y las que compran son a subidísimos precios, que los pagan en pedazos de oro sin cuño $y$ en preciosisimas perlas.... (Libro I, cap. II.)

"HIalsla, hermosisima Auristcla... (Libro I, cap. IV.)

*... la una muchacha de hasta quince años, y la otra hasta treinta; ésta hermosa, pero la muchacha hermosisima..." (Libro I, cap. IV.)

a...aum nté las aguas del mar con las que derramaba de mis ojos.... (Libro I, cap. V.)

a... a cuyo espectáculo también cerró los ojos Auristela con un profundo desmayo, hiciéronse fuente los de Periandro y rios los de todos los circunstantes... (Libro I, cap. V.)

" Vivid felices y luengos años en el mundo, oh dichosos y bellísimos amantes! ¡Coronen presto hermosisimos hijos vuestra mesa...l" (Libro $I$. cap. X.)

"Ol hermosísima Auristela! [Detente, no te precipites a dar lugar en tu imaginación a esta rabiosa dolencia!... (Libro I, cap. XXIII.)

- Por ventura, hermano, está entre esta gente la bellisima Sinforosa?...* (Libro II, cap. II.)

- ¿Por ventura, hermano, esta hermosisina doncella que aquí va es Sinforosa, la hija del rey Policarpo?" (Libro II, cap. II.)

- - Con las cosas divinas - replicó Periandro- no se han de comparar las humanas, las hipérboles alabanzas, por más que lo sean, han de parar en puntos limitados: decir que una mujer es más hermosa que un ángel es encarecinicnto de cortesia, pero no de obligación. Sola en ti, dulcísima herumana mia, se quicbran reglas y cobran fuerzas de verdad los encarecimichtos que se dam a tu herwosura.p (Libro II, cap. II.)

4... primero un sıavisimo son, que hirió nuestros oidos..., luego salió un carro que no sabré decir de qué materia, aunque diré su forma, que cra de una nave rota que escapaba de alguna borrasca; tirábanle doce poderosisimos simios, animales lascivos. Sobre el carro venia una hermosísima dama...* (Libro II, cap. XV.)

4... venia a su lado, asimismo a caballo, una hermosisina mujer...* (Libro II, cap. XVIII.)

-A todas estas pláticas puso silencio un gran rumor que se levantó entre la gente, causado del que hacía un poderosisimo caballo bárbaro.... (Libro II, cap. XVIII.)

* Apenas lubieron puesto los pies los devotos peregrinos en una de las dos entradas que guiau al valle, que forman y cierran las altisimas sierras de Guadalupe...

... cuando vicron al grande y suintuoso mounsterio, cuyas murallas encierran la santisina inngeu de la Emperadora de los Ciclos; la santisima imagen, otra vez, que es libertad de los cautivos, lima de sus hierros y alivio de sus pasiones; la santisima imagen que es salud de las enfermedades... (Libro III, cap. V.)

"Llovian lágrimas de sus ojos, bastantes a bañar las reliquias de su pasión... (Libro III, cap. XVII.) 
"Por Dios, que hace mal el señor gobernador de no mandar que se cubra el rostro desta movible imagen. ¿Quiere, por ventura, que los discretos se admiren, que los tiernos se deshagan y que los necios idolatren?

Con estas alabanzas, tan hipérboles como no uecesarias, pasa adelante el gallardo escuadrón..." (Libro IV, cap. III.)

*... Y ninguna vez salian de casa que no las seguia casi la mitad del pueblo de Roma.n (Libro IV, cap. VI.)

- $\mid$ Ayl -iba diciendo entre si-hermosisima Sigismunda, reina por naturaleza, bellisina por privilegio y por merced de la misma naturaleza..." (Libro IV, cap. XI.)

-Levantóle en este algo más testimonio que debiera, y subió en p:1:itn, con los hipérboles que pudo, las bondades de Persiles." (Libro IV, cap. XII )

Como vemos, la cosecha es nutricla y variada. Quizá por esto, también, Cervantes se planteó críticamente el problema de la hipérbole (separemos, aquí, las hipérboles) cuando escribía el Persiles. Llegó así a decir en un pasaje que, precisamente, he citado: "Las hipérboles alabanzas, por más que lo sean, lian de parar en puntos limitados..." (Libro II, cap. II.) El párrafo está puesto en boca de Periandro, al hablar de la belleza de Auristela. La verdad que la situación está plenamente justificada a través de lo que retratos de Auristela o elogios al personaje han determinado hasta entonces ( $y$ determinarán después). Aunque Cervantes no nos alcance a convencer del todo de que, en efecto, al hablar de Periandro y Auristela se ha parado en "puntos limitados"... 1

Afortunadamente (y no hace falta explicar la contraposición) esta tendencia a perfecciones e idealidades se contrapesa en alguna medicla por personajes y situaciones más concretos, 0 , si preferimos, menos desrealizados. No se trata de pretender almas y cuerpos minúsculos o mezquinos, sino de captar con más tibieza humanidades que corren el peligro de desvanccerse a fuerza de purezas o de las hipérboles con que Cervantes las aureola.

Por supuesto, la hipérbole en el Persiles es distinta (por lo menos en sus líneas principales) que la que aparece en el Quijote. J.a esencial hipérbole de este libro deriva de la "locura» del protagonista; la del

1 Ii. C. Rilcy, al estudiar la hipérbole cervantina, distinguia cntre su uso cn el Quijote y el Persiles de csta manera: "The exceptional, by definition, is no subjet to rule. But how is one to convince the rearler that the case truly is exceptional? The anbivalence is at the root the conic irony which gives coherence to Don Quixole but is mostly absent from the Persiles. Irony allows Cervantes to make the dilcmuna part of his great novel of contradictions..." (E. C. RIIEY, Cervante's theory of the novel, Oxford, 1962, p. I57.) 
Persiles, del halo con que el autor envuelve a la pareja de príncipes, sobre todo en relación a la meta que los peregrinos persiguen ${ }^{1 .}$.

\section{d) La antitesis}

Si no fuera simplificar demasiado, yo diría que, en realidad, todo el Persiles está concebido, aparentemente, como una vasta oposición entre el norte y el sur. Distinción geográfica que divide en forma simétrica los cuatro libros de la obra ${ }^{2}$. Por otra parte, no me olvido que, en otro lugar, tenté la posibilidad de que, con algún fundamento, el norte cervantino esté determinado - como diferencia esencial- por la Fitiopía de Heliodoro.

Sobre esta base, no puede sorprendernos que la antítesis ocupe, como elemento de la expresión cervantina, un sitio importante en su prosa. Conviene aclarar que si la antítesis tiene significación en la totalidad de la obra de nuestro autor, en ninguna otra se da con la frecuencia que vemos en el Persiles.

La explicación ne parece sencilla. Partiendo de las observaciones precedentes, la diferencia de mundos, la lucha continua, el paisaje cambiante, el encuentro y desencuentro de personajes y pasiones, todo

1 Hatzfeld ve bicu, sin duda, cuando destaca que la megalomania caballeresca de Dou Quijote se refleja en hipérboles... No tan bien, cuando, apoyándose en una cita de Rodriguez Marin, considera que tiene posiblemente repercusión en ese rasgo el hecho de haber vivido el autor del Quijote en el sur de Iispaña: -El humor genuino tiene siempre algo de alegre, de plenitud temperamental e imaginativa. Il marco de una expresión legitima, prosaica y leal es demasiado estrecho para él. Sus objetos de atención se le presentan aumentados, y sublimados sus sentimientos. Su expresión se convierte, por tanto, en exageración, en hipérbole... Su comicidad resulta de las inauditas desproporciones entre la voluntad y la posibilidad, sentido de fuerza y debilidad efectiva a las amenazas y los medios de realizar éstas..." (Cf: H. HATZFILD, El "Quijote" como obra de arte del lenguaje, trad. de M. C. DE I., Madrid, 1949, pp. 26I-262.)

2 Cf. con la antitesis en el Quijote, tal como la ve Hatzfeld: “Todos los comentaristas han señalado descle antiguo la posibilidad expresiva, en verdad macrocósmica, de la oposición Don Quijote-Sancho y han visto en ella la contradicción entre el ideal y la realidad, Dios y el mundo, el espíritu y la carne, la poesia y la verdad, etc. Ningumo ha encontrado necesario señalar los matices que esta antitesis, este principal y fundamental contraste, experimenta en el transcurso de la novela... La relación de Don Quijote con Sancho y la de ambos con el mundo entero están formuladas en antitesis, en parte crudas, en parte lummanizadas. (H. HATZFEID, obra citada, pp. 39 y 77.) Por supuesto - aclaro- no itodos» los comentaristas han señalado la radical oposición que les atribuye Hatzfeld. 
favorecía, no cabe cluda, la presencia ineludible de la antítesis. Veamos de nuevo, como corresponde, los ejemplos:

"-iSl, si; éste es el manco sano, el famoso todo, el escritor alegre, y, finalmente, el regocijo de las Musasl" (Prólogo).

No es casual que las primeras palabras que pronuncia Persiles en la novela ofrezcan dos antítesis encadenadas (luz y oscuridad; vida $y$ muerte):

- -Gracias os hago jolı innnensos y piadosos cielosl de que me habéis traido a morir adonde viestra luz vea mi muerte y no adonde estos oscuros calabozos, de donde ahora salgo, de sombras caliginosas la cubran.... ( $\mathrm{Li}$ bro I, cap. I.)

También encontramos el tantas veces repetido contraste entre hielo y fuego, en relación al amor. Esto le dice Rosamunda a Antonio:

"Yo te adoro, generoso joven, y aqui entre estos hielos y nieves, el amoroso fuego me está haciendo ceniza el corazón.... (Libro I, cap. XIX).

$\mathrm{Y}$ así se dirige Croriano a Ruperta, en uno de los episodios del Libro III:

"La bella matadora, dulce enojada, verdugo agradable: ejecuta tu ida, satisface tu enojo, borra y quita del mundo tu agravio, que delante tienes a quien puedes hacerlo.... (I,ibro III, cap. XVII.)

Vemos, en fin, en un breve diálogo entre Auristela y Mauricio no sólo la contraposición de vida y sueño, sino también un vago anticipo (uno, entre muchos) de la famosa comedia de Calderón:

"-De tal manera - respondió Auristela - ha contado sus sueños mi hermano, que me iba haciendo dudar si era verdad o no lo que decia.

A lo que añadió Mauricio:

- Esas son fuerzas de la imaginación en quien suelen representarse las cosas con tanta rchemencia que se aprehenden de la memoria, de manera que quedan en ella, siendo mentiras, como si fueran verdades." ( $\mathrm{Li}$ bro II, cap. XV.)

Otros ejemplos:

C... de modo que, dormido y despierto, era uma muerte dilatada mi vida..." (Libro I, cap. V.) 
4... os suplico que cubráis mi fuego con hielo y me enterréis en esa sepultura.... (Libro I, cap. XX.)

... pero yo espero en los piadosos cjelos que algún dia ha de reducir a sosiego mi desasosiego, y a bonanza mi tormenta..., (Libro II, cap. II.)

-Véisme aqui, señores que me estáis escuchando, hecho pescador $y$ casamentero, rico con mi querida hermana, y pobre sin ella, robado de salteadores y subido al grado de capitán contra ellos: que las vueltas de ni fortuna no tienen un punto donde paren ni término que las eucierren.* (Libro II, cap. XII.)

- Si es verdad, como lo es, ser dulcisina cosa contar en tranquilidad. la tormenta, y en la paz presente los peligros de la pasada guerra, y en la salud la enfernedad padecida, dulce me ha de ser a mi agora contar mis irabajos en este sosiego..." (Libro II, cap. XVII.)

*... yo cantaré, si no canciones alegres, a lo menos, endechas tristes, que cantándolas encanten, y llorándolas alegren." (Libro III, cap. IV.)

*... hombres de poco valor, de fe negra y de peusamientos viles, $y$. para mayor horror y espanto, con los brazos muertos azotan los cuerpos vivos." (Libro III, cap. X.)

- iCuerpo del mundol -respondió el cantivo-. ¿Iis posible que ha de querer el señor alcalde que scamos ricos de memoria, sicndo tan polbres de dinero...? (Libro III, cap. X.)

-Triunfó aquella noche la blanda paz desta dura guerra; volvióse el campo de la batalla en tálamo de desposorio; y del disgusto, el contento.* (Libro III, cap. XVII.)

.... él lleva un volcán en los ojos y una mordaza en la lengua." (Libro IV, cap. XI.)

4... y el gobernador, de alli a cuatro días, le mandó llevar a la loorca por incorregible y asesino, cuya muerte dio la vida a Hipólita, que vivió descle alli adelante." (Libro IV, cap. XIII.)

*Bartolomé el Mancliego y la castellana Luisa se fueron a Nápoles, donde se dice que acabaron mal, porque no vivieron bien. (Libro IV, cap. XIV.)

"Aqui, huyenclo de la guerra, hallé la paz; la hambre que en ese unundo de allá arriba, si así se puede decir, tenia, halló aquí la hartura; aqui, en lugar de los principes y monarcas que mandan el mundo, a quien yo servia, he hallado a estos árboles mudos, que, aunque altos y pomposos, son humildes... (Libro III, cap. XVIII.)

Por descontado, no pretendo que la antítesis tenga en Cervantes ni siquiera en el Persiles, el valor y la persistencia que tiene dentro del conceptismo, o, menos, del cultismo. Pero, de todos modos, es un re curso al que Cervantes suele acudir con cierta frecuencia. $Y$ tanto en la narración propiamente dicha como en los diálogos. Recurso al que se ve empujado, a veces como alarde o retórica, $y$, las más, repito, como una consecuencia de las reiteradas oposiciones que la narración, en todo sentido, le plantea. 


\section{e) Los juegos de palabras}

Siempre fue afecto Cervantes a los juegos de palabras. Por lo común, juegos poco complicados que aparecen en la frase cono gestos más o menos ingeniosos, y que no abultan ni se apretujan. De más está decir que Cervantes se nos muestra a distancia considerable de muchos ingenios barrocos que hicieron de los juegos de palabras motivos fundamentales de sus escritos ${ }^{1 .}$

Dentro de la obra cervantina, el Persiles se distingue también por reflejar el procedimiento con alguna major frecuencia. No demasiado, claro está. Fin última instancia, hasta nos convence de que, en este muestrario final que Cervantes nos da de sus recursos de escritor (y donde más de una vez resalta orgullosamente el deseo de mostrarnos sus condiciones de "escritor"), Cervantes - repito- recurrió un poco más de lo acostumbrado a los juegos de vocablos. Sin afán de abarcar todos los grupos particulares, diré que en el Persiles este recurso literario suele manifestarse, de manera especial, por estos cuatro procedimientos: a) por repeticiún; b) por derivación; c) por proximidad fonética, y d) por proximidad fonética especial (paronomasia).

Veamos ejemplos. Por repetición:

"No te canses, señor mio - dijo la bárbara grande- en referirlos tan por extchso, que podrá scr que te canses o que canscs..." (Libro I, cap. VI.)

"No te admires en ver que te nombre por tu nombre..." (Libro III, cap. I.)

"... aunque este parecer se dividió en pareceres..." (I.ibro III, cap. IV).

"w... vieron que caninaba una peregrina, tan peregrina, que iba sola..." (Libro III, cap. VI.)

«... $\mathrm{Y}$ con razones sobre la razón misma...» (Libro IV, cap. V.)

Juegos de palabras por derivación:

1 A pesar de sus burlas contra la "razón de la sinrazón", también Cervantes -comenta Rafael Lapesa- solia hacer juegos verbales reiterativos. Juegos verbales a los que tampoco fueton ajenos (en no exagerado número), Boscán, Garcilaso, Cetina, los Aldana, Figueroa, Camoens, Herrera, Juan de la Cueva, Jáuregui, Quevedo y otros. (Cf., R. LAPESA, Poesia de cancionero y poesia italianizante, en Strenae a Manuel García Blanco, Salamanca, 1962, p. 273.)

Sobre los juegos de palabras en Cervantes, ver, también, el estudio de HesiruT HatzFend, El "Quijole" como obra de arle del lenguaje (ed. citada, pp. 233-235): y, solre todo, el estudio de ANGir, Rusenbi,AT, La lengua de Cervantes (igualmente citado). 
-Escucha, pues-le fue respondido-, que en las más breves razones te contaré las sinrazones que la fortuna me ha hecho... (Libro I, cap. II) ${ }^{1}$. Arrogante sobre la misma arrogancia, y atrevido tanto como él mismo, porque no se halla con quien compararlo. (Libro I, cap. IV.)

... con adeinán que la pudiera liacer menos hermosa, si es que los accidentes ticnen fuerzas de menoscabar las grandes hermosuras...* (Libro I, cap. XII.)

4... y, en son de decir gracias, te has desgraciado con todo el mundo.* (Libro I, cap. XIV.)

Auristela quedó suspensa, quedó atónita, quedó más triste que la tristeza misma... (Libro I, cap. XX.)

t... que algún día he de reducir a sosiego mi desasosiego..." (Libro II, cap. II.)

1... el pecho de Policarpo anochecia la noche de la mayor tristeza que pudiera inaginarse... (Libro II, cap. XVII.)

c... quise desterrarme y venir a estas setentrionales partes a buscar lugar donde no me alcanzase la infamia de mi infame vencimiento.) ( $\mathrm{Li}$ bro II, cap. XIX.)

"Hizose asi, y de alli a dos días se vieron peregrinamente peregrinos.... (Libro III, cap. I.)

*... y donde el castellano del castillo..." (Libro III, cap. I.)

.... endechas tristes que cantándolas encanten...* (Libro III, cap. IV).

-Verdad debió de decir el predicador que predicaba los días pasados en nuestro pueblo cuando dijo que los cielos y la tierra anunciaban y declaraban las grandezas del Señor... (Libro III, cap. XII.)

Juegos de palabras por proximidad fonética:

a... que si este vientre vomita vivos, yo lo tendré por mulagro. ( $\mathrm{I}, \mathrm{i}$ bro II, cap. II.)

"Pero que después, con la soledad y ociosidad...» (Libro II, cap. III.)

4... las puertas o, por mejor decir, las fuerzas del infierno... (Libro IV, cap. V.)

\section{Juegos de palabras por paronomasia:}

4... a ser monte que llegue a los cielos, llegando a los celos.... (Libro II, cap. VII, primera parte.)

-... la moza es más del suelo que del cielo, y quiere seguir su inclinación, a despecho y pesar de vuestros consejos.» (Libro III, cap. XVIII.)

c... y el otro queda haciendo romera a la ramera de Talavera...) (Iibro III, cap. XIX.)

1 Fácilmente, esta cita nos lleva al conocido párrafo del Quijote de I605. en que Cervantes remeda a Feliciano de Silva. No deja de ser curioso (como se ha probado) que el punto de partida de la burla cervantina esté en una obra drainática, y no en una novela de las tantas que firmó Feliciano de Silvạ. 
Claro que -como digo- es evidente la intención de Cervantes de no extremar demasiado el recurso, y de utilizarlo en forma que no acumule cercanamente un ejemplo con otro. Esto mismo nos está diciendo (si quedara alguna duda) de un manejo consciente, medido. Por supuesto, no considero aquí la mayor o menor felicidad de sus juegos, sino su carácter "literario» y la intención del escritor. Por otra parte, y esto tiene que ver ya con el carácter de la obra, los juegos de palabras responden en Cervantes a sutilezas y alardes expresivos, a comparaciones y muestras de ingenio, y no a chistes y burlas, o a ostentosas muestras de fecundidad lingüística.

\section{f) Las repeticiones intencionadas}

En el Persiles encontramos (como en otras obras cervantinas, sobre todo el Quijote) un uso frecuente de repeticiones intencionadas. De la misma manera, encontramos paralelismos y encadenamientos. Vale decir, recursos de estilo que, si por un lado no alteran mayormente formas características de su lengua, por otro lado, repercuten también, indudablemente, en el tipo de frase larga en que nuestro autor se mueve con mayor comodidad.

En efecto, lo dicho precedentemente nos coloca dentro de algo inconfundible en su prosa. Cervantes, el Cervantes más persistente, necesita espacio para moverse. No es para él la frase breve, hiposa; castigada de elipsis o de una excesiva economía de lenguaje. Mejor dicho, su pensamiento necesita aire. Lo que tiene que decir se ahoga en breve terreno. $\mathrm{Y}$, así como la estructura trimembre y la abundancia de adjetivos (1o hemos visto) contribuyen a marcar formas que explican la amplitud de la frase cervantina, de la misma manera, las repeticiones intencionadas, los paralelismos, los encadenamientos, y hasta las parejas de sinónimos, forman otro especial sector, sector que contribuye también a esa amplitud de frase a que me refiero.

Repeticiones intencionadas:

«Entre estas flechas, entre estas heridas, entre estos golpes y entre estas inuertes estaban juutos la antigua Cloclia, la doncella intérprete, Periandro y Auristela, todos apiñados y todos llenos de confusión $y$ de miedo.» (Libro I, cap. IV.)

(1... que aunque Roma es el cielo de la tierra, no está puesta en el cielo... (Libro II, cap. VII, primera parte.)

"Destas juntas y destos hurtos amorosos, se acortó nui vestido y creció mi infamia, si es que se puede llamar infamia la conversación de los reposados amantes.n (Libro III, cap. III.) 
Monte érades vos; pero monte humilde, que, con las sombras de vuestra industria $\&$ de vuestra discreción os encubriades a los ojos de las gentes.* (Libro III, cap. XIV.)

*Esta es, señoras mías, mi historia; esta mi locura, esta mi enfernnedad...* (Libro III, cap. XX.)

-... tú has sido mi padre, tú mi hermano, tú mi sonubra, tú mi amparo, y, finalmente, tú mi ángel de guarda, y tú mi enseñador y mi maestro, pues me has traldo a esta ciudad, donde he llegado a ser cristiama, como debo." (I,ibro IV, cap. X.)

Un ejemplo de repetición y paralelismo (aparte de algún otro que puede seĩalarse en los ejemplos citados):

1... ella castigó a un enemigo de Dios, y yo quiero castigar a un enemigo que no sé si lo es nujo; a ella le puso el hierro en las manos, el amor de su patria, y a mi me lo pone el de mi esposo." (Libro III, cap. XVII.)

Paralelismos: .

4... y asi, pisando muertos y hollando armas, siguicron al joven bárbaro que los guiaba... (L,ibro I, cap. IV.)

- Seas bien liallada, norte por donde se gulan mis honestos pensamientos y estrella fija que me lleva al puerto doude han de tener reposo mis buenos deseosl" (Libro I, cap. XV.)

iY con esto, los que no son reyes procuran ser virtuosos para serlo, y los que lo son, pugnan por serlo más para no dejar de ser reyes." (Libro $I$, cap. XXII.)

IL mismo dijeron Carino y Solercio, ellos llorando en público, y yo muriendo en secreto. (Libro II, cap. XII.)

Una muestra de paralelismo y encadenamiento:

«A lo que respondió Auristela:

- Mi hermano Periandro es agradecido como principal caballero, y es discreto como andante peregrino: que el ver mucho y el leer mucho aviva los ingenios de los hombres.» (Libro II, cap. VII, primera parte.)

Ejemplos de encadenamiento:

¿La honestidad siempre anda acompañada con la vergüenza, y la vergüenza con la honestidad; y si la una o la otra comienzan a desmoronarse y a perderse, todo el edificio de la hermosura dará en tierra y será tenido en precio bajo $y$ asqueroso. (Libro $I$, cap. XII.)

... Eusebia, yedra de vuestro muro, olmo de vuestra yedra, espejo de vuestro gusto y ejemplo de bondad y agradecimiento. (Libro II, cap. XXI.)

4... bajé por un caracol a unos aposentos bajos de mi casa, y de ellos con facilidad me puse en la calle, $y$ de la calle en el campo, y del campo en no sé qué camino...* (Libro III, cap. III.) 
Por último, aunque no tengan la importancia que tienen en el Quijole, podemos agregar aquí, dentro de este particular grupo de las repeticiones intencionadas, las parejas de sinónimos ${ }^{1}$. Por supuesto, parejas de sinónimos con el ya sabido relativismo con que englobamos los "sinúninos».

Lijemplos:

4... todo lo cual le admiraba y suspeydia..." (Libro I, cap. VI.)

a... cntre las peñas, riscos y escollos de la marina..." (Libro I, cap. VI.)

4... para mayor horror y espauto... (Libro III, cap. X.)

"Dejóla Antonio, sagaz y advertido...* (Libro I, cap. XIX.)

... aguijada del miedo y solicitada del temor... (Libro III, cap. III.)

... dijo que los cielos y la tierra antunciaban y declaraban las grandezas del Seũor... (Libro III, cap. XIII.)

"-Yo, señora, no we acabo de desengañar si esta doncella está loca o cudemoniada, y, por no errar, digo que está endemoniada y loca... (Libro III, cap. XX.)

- i $\Lambda$ y Jesúsl - dijo Ruperta - iY en casa de endemoniados y locos nos apcamos? (Libro III, cap. XX.)

4... caida que dejó vacas y vacias las sillas del cielo..." (Libro IV, cap. V.)

In un pasaje del Persiles dice Cervantes que "no hay razonamiento que, aunçue sea bueno, siendo largo lo parezcal (Libro I, cap. XVIII). $Y$ en otro lugar, hablando de las pláticas, dice que "las que son largas, aunque sean de inportancia, suelen ser desabridas" (Libro II, cap. XXI)

No creo que puedan blandirse contra el propio autor tales razones. In primer lugar, porque la frase de Cervantes no resulta excesivamente larga. En segundo lugar, porque la extensión es, muchas veces, un rasgo puramente externo que, claro está, no puede desatender su contenido. $\mathrm{Y}$, sobre todo, porque este tipo de frase es, sin duda, la que realmente se aviene, como exacto reflejo, al pensamiento cervantino.

\section{g) Las frases hechas}

Quizá el Persiles, entendido dentro de las dimensiones que abarca la novcla, no ofrezca aquí un carácter especial. Quiero decir, no of rezca en sus páginas particularidades llamativas, en relación al común de las

1 Recordicmos que este rasgo del Quijote de $6_{60}$ (ver, antes, ejemplos en el Lazarillo) fue señalado tempranamente, entre otros, por el autor del Quijote apócrifo. "Sinónimos voluntarios", los llama. "No sólo he tomado por medio entremesar la presente comedia con las simplicidades de Sancho Panza, huyendo de ofcuder a nadie, ni de hacer ostentación de sinónimos voluntarios, si bien supiera hacer lo scgundo, $y$ mal lo primero.n (ALONSO FERNANDEZ DE AVELLANEDA, Prólogo al Quijote apócrifo, I6I4.) 
obras. Tampoco, creo, en comparación dentro del grupo aparte que constituyen las obras cervantinas.

Sin embargo, me interesa señalar en este punto unas pocas frases que pueden entrar en la denominación con que encabezo estos párrafos. Sobre todo, porque tienen que ver, indudablemente, con el contenido de la novela.

Pienso, de manera especial, en frases como "mil géneros de muertes» (Libro I, cap. IX), o "mil diferentes géneros de muertes" (Libro I, cap. VI); y en la expresión "quienquiera que seas" o "quienquiera que seáis». Particularmente, en estas últimas ${ }^{1}$, que se repiten de modo llamativo por lo menos seis veces a lo largo del Persiles: ver Libro I, cap. II; Libro I, cap. III; Libro I, cap. IV; Libro I, cap. XI; Libro II, cap. XVIII; Libro IV, cap. II ${ }^{2}$. (Cf. con el Quijote de I605, cap. I, y con El retablo de las maravillas).

Como digo, reparo en "quienquiera que seas" (o "quienquiera que seáis») porque se ligan, explicativamente, al asunto de la obra. En efecto,

1 Vemos, antes en el Peregrino de Iope: «Sedis quien fuéredes (replicb aquel Bárbaro)...* (LOPE DE Viea, El Peregrino en su Patria, Sevilla, 1604, Libro III.) $Y$, más lejos, con el dantesco "aval che tu sie" (Infierno, I, 66) y con libros de caballerias.

2 Como sabemos, Montalbán y Calderón llevaron al teatro el libro de Heliodoro, en sendas obras que llevan un mismo titulo: Los hijos de la fortuna, Tedgenes y Cariclea.

Mie parece, sin embargo, que Calderón tuvo también en cuenta el Persiles cervantino al escribir su comedia. Digo esto porque, precisamente, Calderón repite en varias ocasiones la frase citada:

Persina: $Y$ tii, quien quiera que seas, el que piadoso y benigno eligio al cielo en su amparo (que esto persuade el delirio de un ciego amor) oye ahora lo que antes de ahora te he escrito... (Acto I, escena VI.)

Cariclea: Miente vuestra aleve voz; que a costa de mi inocencia quiere salvar un delito. Hombre, quien quiera que seas...

(Acto II, escena VI.)

$Y$, aunque ya no tenga que ver con dicho ejemplo, reparo en otra coincidencia:

Persina: Antes de pisar la raya de Egipto... (Acto III, escena IV.)

Cf.: "Hicelo así, y en dos dias pisé la raya de Aragón..." (CERvanres, Persiles, Libro I, cap. V.) 
notemos que todas las citas, salvo la última, corresponden a los dos primeros Libros del Persiles. Es decir, a aquellos que se desarrollan en el más borroso e incierto ámbito del norte. Alli, donde los peligros aumentan y, en relación a la singular frase, donde la presencia de nuevos personajes supone, en principio, hostilidad o desconfianza. En tales circunstancias, la frase encierra por lo común una presentación y una advertencia...

Ińn cambio, la ausencia de tales expresiones en los dos últimos libros (los referidos al sur) está de acuerdo con un itinerario menos expuesto. No porque falten incidentes y aventuras (de sobra sabemos que no), sino porque esos incidentes y aventuras se desarrollan dentro de un marco nuás poblado, mejor conocido o previsto. La diferencia es, asf, clara.

\section{h) Otros rasgos}

Posiblemente, al referirme a "otros rasgosi corro el peligro de minimizar cl conjunto. De todos modos, me parece oportuno agregar algunas particularidades que, sin corresponder a las más espectaculares y reiteradoras, contribuyen también, me parece, a individualizar el Persiles.

Pienso, sobre todo, en el uso del hipérbaton, que -creo-suele aparecer con mayor frecuencia que en el Quijote de I605. Quiero decir, como construcción algo más extremada, sin llevarnos, por eso, a la acumulación y complejidad de los hipérbatos cultistas.

Veamos ejemplos:

"Alongados, pues, un tanto de la isla, como se ha dicho, admiraron la nave con flámulas y gallardetes, que ellos azotando el aire y ellas besando las aguas, hermosisima vista hacian." (Libro I, cap. II.)

a... me depararon una muchacha bárbara, de hasta edad de quince años, que por entre las peñas, riscos y escollos de la marina, pintadas conchas y apetitosos mariscos andaba buscando. (Libro I, cap. VI.)

a... y no lejos estaba un puerto capacisimo de muchos bajeles, en cuyas aguas, como en espejos claros, se estaba mirando una ciudad populosa, que, por una alta loma, sus vistosos edificios levantaba.n (Libro II, cap. II).

Como vemos, no se trata de ejemplos complejos (como los que resaltan en Góngora, para citar un modelo obligado). Sin embargo, revelan la inclinación de Cervantes por un esquema que procura hacer destacar el verbo al final de la oración. $Y$, cosa curiosa, de nuevo aquí los ejemplos aparecen (o aparecen con más nitidez) en los dos primeros Libros... 
Acercándonos ahora - dentro de este sector- a características que repercuten, también, en el párrafo amplio de Cervantes, debemos mencionar el uso del polisíndeton. Dentro de este sector que englobo con el nombre de uotros rasgos» - digo- porque, si bien aparece, está lejos del primer plano que corresponde a los rasgos que hemos visto en un orden indudable de importancia y reiteración (la estructura trimembre y el adjetivo, sobre todo).

- Veamos algunos ejemplos del polisíndeton en el Persiles:

"Dejóla Antonio, sagaz y advertido; volvióse Rosamunda, y él siguió su caniino; pero no halló en él cosa que le asegurase, porque las nieves eran muchas, y los caminos ásperos, y la gente ninguna, y advirtiendo que, si adelante pasaba, podja perder el camino de vuelta, se volvió a juntar con la compañia." (I,ibro I, cap. XIX.)

4... bajé por un caracol a unos aposentos bajos de mi casa, y de ellos con facilidad me puse en la calle, y de la calle en el campo, y del campo en no sé qué camino; $y$, finalmente, aguijada del miedo y solicitada del temor, como si tuviera alas en los pies, caminé más de lo que prometia wi flaqueza.... (Libro III, cap. III.)

"Discurrieron por la verdad de la creación del hombre y del mundo y por el misterio sagrado y amoroso de la Encaruación, y cou razones sobre la razón misma.... (Libro IV, cap. V.)

En fin, el uso de un lenguaje metafórico que parece haber aprendido singularidades de la lengua poética cultista. Quiero decir, de una escuela que venía librando ruidosas batallas cuando Cervantes elaboraba el Persiles.

Por supuesto, en el caso especial de nuestro novelista, me refiero a ejemplos que escapan a una ceñida reminiscencia o a semejanzas ya mencionadas especialmente en otro estudio, al hablar de Cervantes y Góngora.

No suelen ser corrientes en Cervantes - repito- metáforas como las siguientes:

.... midiéndole la boca y los ojos con sus hermosos labios...* (Libro II, cap. IX.)

.... y si aqui nos saltea el hielo, quedamos empedrados en estas aguas (Libro II, cap. XVI).

4... no se olvidó de que pintase verse empedrados en el mar helado...* (Libro III, cap. I.)

4... que la verdura de tus años y el gallardo brlo de tu persona, con muchas batallas te amenazan...v (Libro, II, cap. IX.)

"La ribera de wna isla barramos..." (Libro II, cap. X.)

"Barrlawos todos los mares..." (Libro II, cap. XX.)

a... y los bárbaros, que de no muy lejos lo miraban quedaron más suspensos, y en un momento coronaron la ribera, armados de arcos y saetas...* (Libro I, cap. II.) 
"Estando en esto, me pareció, por entre la dudosa luz de la noche, que la peña que me servía de puerto se coronaba de los mismos lobos que en la marina habla visto... (Libro $I$, cap. V.)

"flícclo asl $y$ en dos dlas pisé la raya de Aragón.... (Libro $I$, cap. V.)

Abraź Periandro a todos los que en el barco venlan, casi preñados los ojos de lágrimas.... (Libro I, cap. III.)

Metáforas que, por su ubicación en la obra, reafirman una vez más la especial distinción a que vengo aludiendo. Vale decir, su presencia o predominio en los dos primeros Libros del Persiles, que se refieren precisamente al vago mundo nórdico.

Iin general, deștaco en las metáforas del Persiles una intención con frecuencia "culta", intención en la que confluyen ansias de novedad, singularidad y alarde. $\mathrm{Y}$ todo esto, dirigido por la gravedad, apenas alterada, del asunto. De tal manera, con apreciable diferencia en relación al juego imaginativo (y desarrollado, sobre todo, en comparaciones) que caracteriza al Quijote de I605. Juego disparado, alli, en la burla, en la sátira, en lo pintoresco.

\section{Conclusión}

A través de los ejemplos, que respaldan adecuadamente las peculiaridades scĩaladas, creo que podemos ahora sacar las conclusiones.

Lifectivamente, el Persiles nos muestra, sin lugar a dudas, que Cervantes extremó aquí su habilidad de "escritor». A veces, hasta nos da la impresión de que quisiera mostrar, en una época de llamativas individualidades literarias, que se hacían notar, precisamente, por sus alardes y espectacularidades (reparemos en lo que significan los quince prineros años del siglo XVII español), Cervantes nos da la impresión, repito, de que él aspira también a salir a la palestra, sin temor a rivales más o menos encumbrados. Con otras palabras: mostrar que a la inventiva y gracejo que se le reconocian, podía agregar también (y era la ocasión) virtudes que hasta entonces no había mostrado, o habia mostrado poco. Debemos tener presente que el punto casi obligado de confrontación ha de ser el Quijote de I605, como obra que ofrece alguna perspectiva dentro de la plenitud cervantina, y como género semejante o afín. E1 Quijote de I605, más que las Novelas Ejemplares (sobre todo algunas, cercanas a la obra de I605) y, por supuesto, que el Quijote de I6I5.

Por lo pronto, es digno de notarse que el Cervantes que escribe el Persiles atiende más que el que escribe el Quijote de 1605 al instrumento de la lengua. Digo (repito), es más cuidadoso, más «artista», en el sentido corriente del término. (Por cierto que, a la inversa, no pretendo señalar 
aquí los "defectos" del Quijote, empeño a que tan afectos - no sin algo de paradoja - eran cervantistas del siglo $\mathrm{xIx}$ ).

Claro que el estilo literario no se logra, o no se logra sólo, a través del rigor y el compás, a través del frío uso de la lengua. Cervantes lo prueba de manera palmaria en sus dos obras. Por encima de "descuidos", brilla en el Quijote de 1605 una lengua viva, rica, con un gracejo que se identifica con lo esencial de su asunto y personajes, con ese mundo que construye toda auténtica novela.

E1 Persiles, que es distinto, en tantos aspectos, del Quijote de I605, lo es también - a menudo- en lo que trasunta del escritor Cervantes. Sin embargo, serfa injusto (lo hemos visto) el pretender establecer una diferencia radical entre las dos obras. Explicablemente, ámbito e incidentes más cercanos, en el itinerario mediterráneo, sirven también para acercarlas. Quizá de manera insensible, los dos últimos libros del Persiles (sobre todo, el tercero) nos aproximan al inconfundible estilo cervantino. $O$ entramos ya abiertamente en él.

Con otras palabras, es muy posible que en estas partes del Persiles el ámbito más propicio, una fuerza que aún pujaba en él, y la unueva maestria" adquirida y ensayada por Cervantes, al fusionarse armónicamente, es muy posible - sospecho- que determinen muchas de las mejores páginas de la novela. Esas que la crítica recuerda con frecuencia no sólo dentro del Persiles, sino también dentro de la obra total del autor... Ya hemos visto cómo Menéndez y Pelayo, en recordado juicio, hacía hincapié en esos últimos Libros del Persiles, si bien para realzarlos debidamente cometía la injusticia de condenar, casi sin atenuantes, todo lo anterior ${ }^{1}$. Y después de Menéndez y Pelayo (no digo, que a través de éste), salvo algunas excepciones, la crítica ha mantenido esta polaridad fundamental al juzgar a la obra póstuma cervantina. Como hemos visto, pretendo mostrar que no es así, aunque no deje de apuntar, explicablemente, diferencias apreciables en las dos partes esenciales del libro.

Detengámonos ahora en este aspecto. Hemos visto también cómo las singularidades mayores (de motivos "nuevos», de lengua poética, de elementos retóricos) corresponden a los dos primeros Libros del Persiles. Vale decir, a aquellos que desarrollan las aventuras marítimas en un nebuloso norte.

Contraponiendo asi, norte y sur, ¿se marcan, de ese modo, dos etapas en la elaboración de la obra? No sería posible afirmarlo, con los ele-

1 Cf., MLntendez y Perayo, El Quijolen y la cultura literaria de Cervantes, en Estudios de crttica histórica y literaria, I, Buenos Aires, 1944, p. 336. 
mentos a nuestro alcance, por más que haya planteado yo la posibilidad de que el comienzo del Persiles (o, mejor, la idea germinadora) pudo estar cerca del Peregrino de Lope. De todos modos, en este juego de acciones y reacciones, la cronología nos llevaría cerca del Quijote de I605, y poco o nada nos servirfa al enfrentar las dos obras cervantinas.

Puede ser que el asunto haya empujado tempranamente al autor a las diferencias más notorias. Puede ser. A su vez, señalar diferencias entre los dos primeros Libros y los dos últimos del Persiles (igualmente lo hemos visto) es válido siempre que no exageremos mucho la nota.

Repito: hay un estilo general del Persiles (conviene reparar ell ello), si bien las particularidades más extremadas (algunos elementos cultistas, rasgos distintos de la lengua) corresponden casi siempre a los dos primeros Libros. Esto es lo que resalta en forma más nítida. Por descontado que hay valores positivos (jy tántos!) en la lengua del Persiles. Esos que -quiero también defenderlos- pueden rastrearse igualmente desde el comienzo de la obra. Nunca será demasiado redundante reiterar este siguo de la novela, aunque tengamos que luchar con juicios de peso y con nombres imponentes de la crítica literaria hispánica.

Es indudable que las bellezas del Persiles, por diferentes motivos, no son fáciles de entregar. $Y$ que el problema, para todo lector, está, además en sobreponerse a la estructura de la novela y a los vaivenes (de todo tipo) que caracterizan las aventuras marítimas que repercuten, creo, en la lengua de la obra.

Probadas están las virtudes cervantinas en el humor, la ironía, el gracejo familiar, la acogedora humanidad, "la discreción", esas virtudes que habían encontrado ancho campo en la mayoría de sus obras $\mathrm{y}$, de manera, especial en El Ingenioso Hidalgo Don Quijote de la Mancha. Por motivos bien comprensibles, esas cualidades no se reflejan con amplitud en el Persiles. Con todo, aparte de que no desaparecen, el libro póstumo nos muestra otras virtudes dentro del desarrollo que particulariza a la novela. Su gravedad necesitaba otros elementos. El tema fundamental de la peregrinación, demorada por múltiples aventuras e incidentes, no podía tampoco perder de vista la meta fijada por los peregrinos. De esta manera, también, se fijan rasgos de la lengua (el escritor los fija) acorde con el meollo de la obra y el sentido que la vertebra.

Todo esto configura la lengua de esta singular producción cervantina. Singular como tema, como ofrenda religiosa, como alarde artístico, $y$ aun por las circunstancias excepcionales en que su autor le dio fin. 